\title{
MEASURING NON-ECONOMIC WELL-BEING ACHIEVEMENT
}

\author{
BY MARK McGilliVRaY* \\ World Institute for Development Economics Research, United Nations University, Helsinki
}

\begin{abstract}
Income per capita and most widely reported, non- or non-exclusively income based human well-being indicators are highly correlated among countries. Yet many countries exhibit higher achievement in the latter than predicted by the former. The reverse is true for many other countries. This paper commences by extracting the inter-country variation in a composite of various widely-reported, non-income-based well-being indices not accounted for by variations in income pre capita. This extraction is interpreted inter alia as a measure of non-economic well-being. The paper then looks at correlations between this extraction and a number of new or less widely-used well-being measures, in an attempt to find the measure that best captures these achievements. A number of indicators are examined, including measures of poverty, inequality, health status, education status, gender bias, empowerment, governance and subjective well-being.
\end{abstract}

\section{INTRODUCTION}

It is common to treat human well-being as a multidimensional concept, enveloping diverse, separable or behaviorally distinct components, domains or dimensions (Finnis, 1980; Nussbaum, 1988; Sen, 1990; UNDP, 1990-2004; Doyal and Gough, 1993; Galtung, 1994; Cummins, 1996; Qizilbash, 1996; Stewart, 1996; Narayan, 2000; Alkire, 2002, among many other studies). ${ }^{1}$ It is in particular thought to be a much richer or vital concept than economic well-being: much of the literature is justifiably emphatic about this point. Accordingly, there is a long history of efforts to both refocus attention away from the established, although invariably far less than perfect, monetary measures of national economic wellbeing achievement and to better capture non-economic well-being achievement. A plethora of indicators of national well-being achievement has been proposed for these purposes. Indicators of health and educational status are most widely-used in inter-country ordinal and cardinal assessments of national well-being achievement, and are now available for diverse samples of 160 or more countries (see

Note: This paper is linked to a broader program of research conducted at WIDER on Inequality, Poverty and Human Development. Its origins are in conversations with Graham Pyatt and Howard White during 1994, when the author was a visiting researcher at the Institute of Social Studies in The Hague, The Netherlands. The author is grateful to James Copestake, David Fielding, Ian Gough, Nanak Kakwani, Massoud Karshenas, Mozaffar Qizilbash, Oliver Morrissey, Mansoob Murshed, Farhad Noorbakhsh, Matthew Odedokun, Mariano Rojas, Richard Ryan, Tony Shorrocks, Frances Stewart, Subbu Subramanian, Erik Thorbecke, Rob Vos, Guanghua Wan, Adrian Wood and two anonymous referees for useful comments on earlier versions of this paper. The author is especially grateful to Stephan Klasen for very insightful comments relating to the measurement error adjustment and hypothesis testing, as conducted in the paper. The usual disclaimer applies.

* Correspondence to: Professor Mark McGillivray, World Institute for Development Economics Research, United Nations University Katajanokanlaituri 6 B, 00160 Helsinki, Finland. (mark@wider.unu.edu).

${ }^{1}$ For the purposes of this paper notions such as human well-being, quality of human life, human development, basic human needs fulfillment are treated as synonymous. 
UNDP, 2003). Multidimensional indicators are also available for similar samples, based either solely or predominantly on these indicators, and include the Physical Quality of Life Index (PQLI) and the very well-known Human Development Index (HDI).

As valid as their conceptual justifications might be, these standard indicators are often highly correlated, both ordinally and cardinally, among countries with income per capita, the most accepted measure of economic well-being achievement (Hicks and Streeten, 1979; Larson and Wilford, 1979; McGillivray, 1991; McGillivray and White, 1993; Srinivasan, 1994; Noorbakhsh, 1998; Cahill, 2004). This is especially the case for large, diverse samples of countries, much to the frustration or disappointment of some proponents of these indicators. ${ }^{2}$ Inter-country variation in non- or non-exclusively economic well-being achievement, measured using these standard measures is, therefore, well predicted by variation in economic well-being. An implication of this relationship is that the standard non-economic or non-exclusively economic measures might not capture the richness or vitality of the well-being concept, giving an incomplete picture of it or at least the part of it that they are intended to capture. The contribution of the standard non-economic measures has been questioned on these grounds, with some commentators going so far as to claim they are empirically redundant vis-à-vis income per capita. ${ }^{3}$

Yet a simple and instructive point has been given insufficient attention in the literature. While there is a high correlation between income per capita and the standard non- or non-exclusively economic indicators in large and diverse samples of countries, some countries perform better in the latter than predicted by the former and some countries perform worse. What would seem, therefore, to be more interesting and informative, than correlations between indicators, is that variation in measures of standard non- or non-exclusively economic well-being achievement not accounted for by income per capita. Amartya Sen, in various publications, and the UNDP, in its Human Development Reports, address this variation, but stop short of providing a formal analysis of it. ${ }^{4}$ A formal measure of this well-being achievement, on which international comparisons might be based, would thus appear to be warranted. Among the insights provided by such a measure is the systematic identification of those countries that have better non-economic well-

\footnotetext{
${ }^{2}$ One can speculate why this might be so, but it is entirely reasonable to posit that higher per capita incomes facilitate private and public expenditure on goods relevant to higher non-economic well-being achievement. Smaller country samples yield much lower correlation coefficients, although in most cases these coefficients are statistically significant. Larger correlations do not necessarily hold for samples of individuals or households at the sub-national level, however (see, for example, Klasen, 2000). As such it must be emphasized that the context referred to in this paper is for countries, not individuals or households.

${ }^{3}$ See Larson and Wilford (1979), McGillivray (1991), McGillivray and White (1993) and Cahill (2005). The redundancy label has been assigned on the basis of correlation coefficients between the non-economic indicators and per capita income typically ranging from the low 0.70 s upwards. Larson and Wilford (1979), for example, considered the PQLI to be empirically redundant based on the correlation between it and GNP per capita of 0.776. McGillivray (1991) drew this conclusion for the HDI based on a correlation coefficient between it and GNP per capita of 0.889 . More generally, it is not uncommon for correlations between non-economic or non-exclusively economic indicators to range from 0.70 to 0.90 or higher.

${ }^{4}$ See, for example, Drèze and Sen (1991). The UNDP examines this variation by reporting the difference between each country's GDP per capita and HDI rankings (see, for example, UNDP, 2004, pp. 139-42).
} 
being achievement than their economic achievement predicts. This information is important if we accept that there is more to well-being achievement than what has been achieved in its economic sphere. It also allows us to begin to ask why some countries do better in this regard than others.

This paper commences by extracting, using principal components analysis, the maximum possible information from various standard national non-economic wellbeing achievement measures. It then empirically identifies the variation in this extraction not accounted for by variation in income per capita, in the form of a variable called $\mu_{i}$. This variable is the residual yielded by a cross-country regression of the extraction on the logarithm of PPP GDP per capita. $\mu_{i}$ is interpreted inter alia as a measure of non-economic human well-being achievement per se, in the sense that it captures well-being achieved independently of income. Given that $\mu_{i}$ is purely a statistical construct, obtained econometrically, the paper then looks at correlations between this measure and variants of it and other well-being or well-being related indicators, in an attempt to find the variable or group of variables that best captures non-economic well-being achievement. It should be emphasized that this is a pure measurement exercise, in that inferences regarding causality are not drawn explicitly. It is of potential practical benefit, however, as it provides a case for allocating more resources to the collection and reporting of the variables, especially if the variable or variables are available or reported for relatively small samples of countries. Alternatively, it provides a case for more use of the variables in well-being assessments if they are available for reasonably large samples of countries. Among the measures not as widely reported or available across countries or not as widely used as those mentioned above, two variables perform best in this regard. One is a measure of gender empowerment and the other is a measure educational attainment. It is however found that none of these measures perform consistently better than a very widely used one, that measure being adult literacy.

\section{Non-Economic Well-Being Achievement}

Let us commence with the following composite, "standard" index of noneconomic well-being for country $i$ :

$$
W_{i}=\sum_{k=1}^{m} \Phi_{k} x_{k, i}^{t} \quad i=1, \ldots, n .
$$

where $x_{k, i}^{t}$ are appropriately transformed values of the well-being indicators $x_{k, i}$ and the $\Phi_{k}$ are weights. The $x_{k, i}$ are "standard" non-economic well-being indicators. Characterized above, these indicators are those commonly used and reported, available for a large number of countries and typically highly correlated with income per capita. $W_{i}$ captures that maximum obtainable information from the $x_{i, k}$ subject to an appropriate condition. This is achieved by choosing the $\Phi_{k}$ that maximize the variance of $W_{i}$ subject to a normalization condition. $\Phi_{k}$ are therefore obtained by principal components analysis, with $W_{i}$ being the first principal component extracted from the $x_{k, i}^{t}$ and $\Phi_{k}$ being an $(\mathrm{m} \times 1)$ eigenvector. The corresponding eigenvalue is $\lambda_{k}$ and the normalization condition is that $\Phi_{k}^{2}$ equals $\lambda_{k}{ }^{5}$

${ }^{5}$ Ram (1982), Ogwang (1994) and Lai (2000) also use the principal components technique to derive well-being measures. 
$W_{i}$ as a standard non-economic measure will be highly correlated with income per capita. Our task is to extract from it that information not predicted by economic well-being, as captured by some measure of income per capita. The following regression equation is therefore estimated:

$$
W_{i}=\alpha+\beta \ln y_{i}+\mu_{i}
$$

where $\ln y_{i}$ is the logarithm of income per capita. The logarithm is used to reflect diminishing returns to the conversion of income into economic well-being. The use of logarithmic values of is consistent with the well-known Atkinson formula for the utility or well-being derived from income. This formula is written as follows:

$$
W\left(y_{i}\right)=\frac{1}{1-\varepsilon} y_{i}^{1-\varepsilon}
$$

where $W\left(y_{i}\right)$ is the utility or well-being derived from income and $\varepsilon$ measures the extent of diminishing returns. As $\varepsilon$ approaches one $W\left(y_{i}\right)$ becomes the logarithm of $y_{i}{ }^{6}$

The error term from (2), $\mu_{i}$, is central to our analysis. It is by definition orthogonal with respect to $\ln y_{i}$, and as such is not subject to the criticism that it reveals disappointingly little additional information in inter-country well-being than income per capita. More pointedly, it is interpreted as a measure of non-economic or income-independent human well-being achievement. It is also interpreted, possibly contentiously, as a measure both of the success in converting economic wellbeing into non-economic well-being and of the non-economic well-being component, dimension or domain within the space of $W_{i}$.

\section{Estimating $\mu_{i}$ : Data And Results}

The chosen components of index $W_{i}$ prior to transformations are years of life expectancy $\left(x_{1, i}\right)$, the adult literacy rate $\left(x_{2, i}\right)$ and the gross school enrolments ratio $\left(x_{3, i}\right)$. The measure of income is PPP GDP per capita. Data on these variables are taken from the UNDP's Human Development Report 2002 (UNDP, 2002). These variables are the components of the HDI. $W_{i}$ therefore shares some similarities with the HDI. ${ }^{7}$ They are available for a sample of 173 countries and are very widely

\footnotetext{
${ }^{6}$ For our current purposes income is seen as a well-being or welfare indicator in its own right, hence the use of the Atkinson formula. But it is also seen as a means for converting economic well-being into non-economic well-being. Allowing for diminishing returns is justified given the boundedness of many non-economic indicators and the increasing costs associated with greater achievement in others (such as life expectancy). It is recognized that selecting values for $\varepsilon$ can be contentious, and for this reason alternative transformations of $y_{i}$, obtained from (3) but with different values of $\varepsilon$, are also used later in this paper. Anand and Sen (2000) provide a detailed discussion of this issue in the context of the HDI.

${ }^{7}$ The HDI is a weighted average of life expectancy, adult literacy, gross school enrolment and the logarithm of PPP GDP per capita, each scaled within theoretical ranges of zero and one-hundred. The first and fourth of these variables are assigned weights of one-third, while the second and third variables are assigned weights of two-ninths and one-ninth, respectively. It follows that $W_{i}$, differs from the HDI in that it assigns different weights to each variable (income per capita receives a weight of zero through its exclusion) and that the variables are transformed using a different procedure, outlined below. Ranis et al. (2000) use a similar index, which is identical to the HDI in all respects other than assigning a zero weighting to income per capita. $W_{i}$, is preferred here mainly because it captures more variation in the component variables but also because its weights are less arbitrary (although of ambiguous theoretical interpretation).
} 
TABLE 1

Zero-order (Pearson) Correlation Coefficients between Commonly-used Well-Being INDICATORS $(N=173)$

\begin{tabular}{llccccc}
\hline \hline & $\begin{array}{c}\text { Life } \\
\text { Expectancy } \\
\left(x_{1, i}\right)\end{array}$ & $\begin{array}{c}\text { Adult } \\
\text { Literacy } \\
\left(x_{2, i}\right)\end{array}$ & $\begin{array}{c}\text { Gross } \\
\text { Enrolment } \\
\left(x_{3, i}\right)\end{array}$ & HDI & $\begin{array}{r}\text { PPP GDP } \\
\text { per capita } \\
(\log )\left(\ln y_{i}\right)\end{array}$ \\
\hline Life expectancy & $\left(x_{1, i}\right)$ & 1.000 & & & & \\
Adult literacy & $\left(x_{2, i}\right)$ & 0.726 & 1.000 & & & \\
Gross enrolment & $\left(x_{3, i}\right)$ & 0.736 & 0.803 & 1.000 & & \\
HDI & & 0.925 & 0.870 & 0.881 & 1.000 & \\
PPP GDP per & $\left(\ln y_{i}\right)$ & 0.794 & 0.701 & 0.792 & 0.923 & \\
$\quad$ & & & & & & \\
\hline
\end{tabular}

TABLE 2

Rank-order (Spearman) Correlation Coefficients between Commonly-uSed Well-Being INDICATORS $(N=173)$

\begin{tabular}{llccccc}
\hline \hline & $\begin{array}{c}\text { Life } \\
\text { Expectancy } \\
\left(x_{1, i}\right)\end{array}$ & $\begin{array}{c}\text { Adult } \\
\text { Literacy } \\
\left(x_{2, i}\right)\end{array}$ & $\begin{array}{c}\text { Gross } \\
\text { Enrolment } \\
\left(x_{3, i}\right)\end{array}$ & HDI & $\begin{array}{c}\text { PPP GDP } \\
\text { per capita } \\
\left(\ln y_{i}\right)\end{array}$ \\
\hline Life expectancy & $\left(x_{1, i}\right)$ & 1.000 & & & & \\
Adult literacy & $\left(x_{2, i}\right)$ & 0.724 & 1.000 & & & \\
Gross enrolment & $\left(x_{3, i}\right)$ & 0.715 & 0.773 & 1.000 & & \\
HDI & & 0.938 & 0.841 & 0.833 & 1.000 & \\
PPP GDP per & $\left(\ln y_{i}\right)$ & 0.840 & 0.695 & 0.780 & 0.938 & \\
$\quad$ capita (log) & & & & & & \\
\hline
\end{tabular}

used. Moreover, as Tables 1 and 2 show, they are quite highly correlated with each other, with PPP GDP per capita and the HDI as a whole. The Pearson (zero-order) coefficients between these variables and the logarithm of PPP GDP per capita in Table 1 range from 0.701 to 0.794 and the corresponding Spearman (rank-order) coefficients in Table 2 range from 0.695 to 0.840 .

Results of the principal components analysis, which is based on the transformed components, $x_{k, i}^{t}$, are shown in Table $3 .^{8} W_{i}$, the first principal component performs very well in extracting information from the three component variables, capturing 84 percent of the eigenvalues. The component variable weights $\Phi_{k}$ are

${ }^{8}$ The principal components analysis was conducted using the computer program SHAZAM, which allows the analysis to be done on a number of alternative matrices. The correlation matrix was chosen, which is appropriate when the original variables are measured in different units, as is the case with the $x_{k, i}$. This dictated that the $x_{k, i}^{i}$, in equation (1) above, from which $W_{i}$ were extracted, were obtained through the following transformation of the $x_{k, i}$.

$$
x_{k, i}^{t}=\frac{x_{k, i}-\bar{x}_{k, i}}{\left[\sum_{i=1}^{n}\left(x_{k, i}-\bar{x}_{k, i}\right)^{2}\right]^{\frac{1}{2}}}
$$

where the bar denotes a mean value. This is a linear transformation. For further details see Whistler et al. (2001). 
TABLE 3

Principal Components Analysis Results

\begin{tabular}{|c|c|c|c|}
\hline & \multicolumn{3}{|c|}{ Principal Components } \\
\hline & $\begin{array}{c}\text { First } \\
\left(P C_{1, i}=W_{i}\right)\end{array}$ & $\begin{array}{c}\text { Second } \\
\left(P C_{2, i}\right)\end{array}$ & $\begin{array}{l}\text { Third } \\
\left(P C_{3, i}\right)\end{array}$ \\
\hline Eigenvalue & 2.510 & 0.293 & 0.197 \\
\hline Cumulative percentage of eigenvalues & 83.654 & 93.424 & 100.000 \\
\hline \multirow{3}{*}{$\begin{aligned} \text { Component weights }\left(\Phi_{k}\right): & \text { Life expectancy }\left(x_{1, i}\right) \\
& \text { Adult literacy }\left(x_{2, i}\right) \\
& \text { Gross entrolment }\left(x_{3, i}\right)\end{aligned}$} & 0.565 & -0.824 & -0.051 \\
\hline & 0.582 & 0.441 & -0.683 \\
\hline & 0.585 & 0.356 & 0.729 \\
\hline
\end{tabular}

TABLE 4

Correlation Coefficients between Well-Being Indicators

\begin{tabular}{lccc}
\hline \hline & \multicolumn{2}{c}{$\begin{array}{c}\text { Well-Being Index } \\
\left(W_{i}=P C_{1, i}\right)\end{array}$} \\
\cline { 3 - 4 } & & Zero-order & Rank-order \\
\hline Life expectancy & $\left(x_{1, i}\right)$ & 0.895 & 0.894 \\
Adult literacy & $\left(x_{2, i}\right)$ & 0.923 & 0.908 \\
Gross enrolment & $\left(x_{3, i}\right)$ & 0.927 & 0.905 \\
HDI & & 0.976 & 0.956 \\
PPP GDP per capita $(\log )$ & $\left(\ln y_{i}\right)$ & 0.833 & 0.838 \\
\hline
\end{tabular}

very similar, varying from 0.565 to 0.585 . Correlation coefficients between $W_{i}$, and its component variables, shown in Table 4, are all very high, ranging from 0.895 to 0.927 and 0.894 to 0.908 for the zero- and rank-order coefficients, respectively. Each of the preceding results are consistent with the rather high correlations between the three component variables reported above. $W_{i}$ is also very highly correlated with the HDI and, pertinently, with $\ln y_{i}$. The zero-order and rank-order coefficients between $W_{i}$ and the HDI are 0.976 and 0.956 , respectively. The corresponding coefficients between $W_{i}$ and $\ln y_{i}$ are 0.833 and 0.838 , respectively. A scatter plot of $W_{i}$ and PPP GDP per capita are shown in Figure 1.

Regressing $W_{i}$, on $\ln y_{i}$ yielded the following equation:

$$
\hat{W}_{i}=\underset{(-19.50)}{-0.755}+0.089 \ln y_{i} .
$$

The numbers in parentheses are $t$ ratios. The $R^{2}$ and $\bar{R}^{2}$ are 0.694 and 0.692 , respectively. Estimates of $\mu_{i}$ are shown, along with values of $W_{i}$ and all other variables mentioned above in Appendix Table A1. Correlation coefficients between $\mu_{i}$ and the standard non- or non-exclusively economic indicators are shown in Table 5. Of the latter variables, that variable most highly correlated with $\mu_{i}$ is adult literacy. Those countries with the 15 highest and 15 lowest residual values are shown in Table 6. High residual values indicate that countries do better in terms of non-economic, or non-income predicted, well-being achievement. The group of countries that does best in terms of this well-being is dominated by those which either still have or in their recent pasts have had non-market, centrally planned 


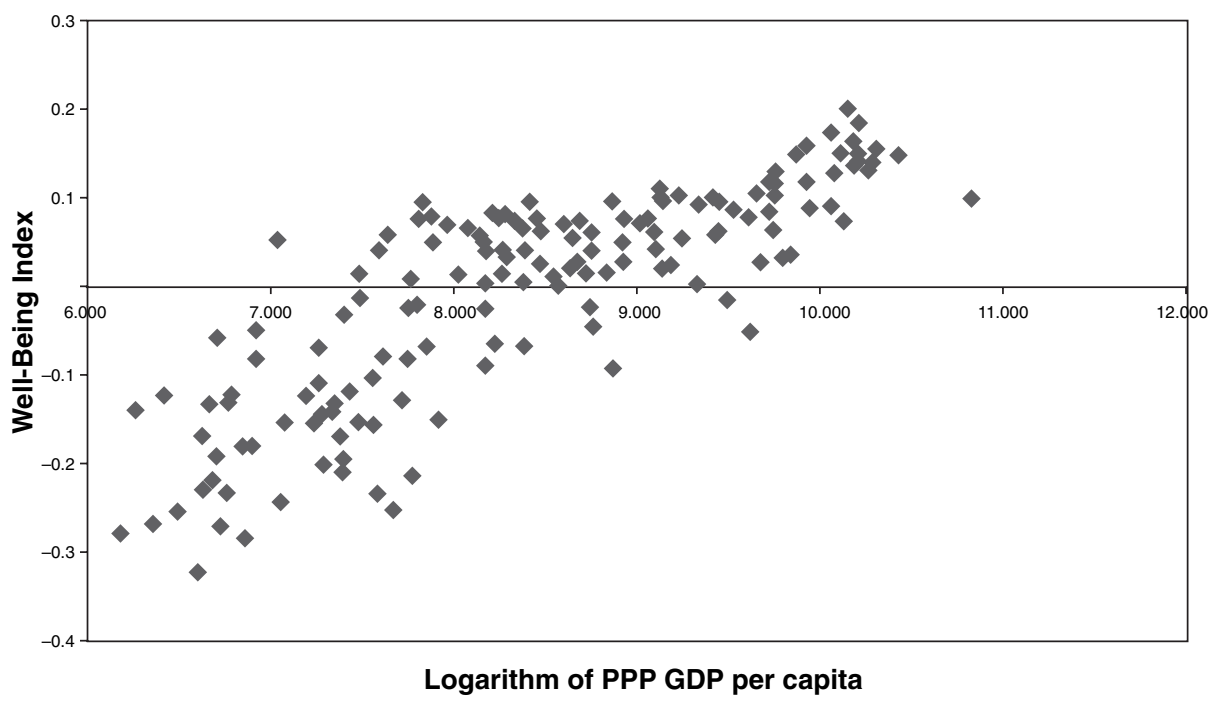

Figure 1. Scatter Plot of Well-Being Index and Income per capita

TABLE 5

Correlations Between $\mu_{i}$ AND Well-Being Indicators

\begin{tabular}{lccc}
\hline \hline Variables & Zero-order & Rank-order & $n$ \\
\hline HDI & $0.373^{*}$ & $0.242^{*}$ & 173 \\
Life expectancy $\left(x_{1, i}^{t}\right)$ & $0.421^{*}$ & $0.262^{*}$ & 173 \\
Adult literacy $\left(x_{2, i}^{t}\right)$ & $0.612^{*}$ & $0.513^{*}$ & 173 \\
Gross enrolment $\left(x_{3, i}^{t}\right)$ & $0.482^{*}$ & $0.398^{*}$ & 173 \\
Well-Being Index $\left(W_{i}\right)$ & $0.554^{*}$ & $0.438^{*}$ & 173 \\
\hline
\end{tabular}

Note: *Significantly different from zero at the $90 \%$ confidence level or greater.

economies. Eleven of the top 15 and each of the top ten countries in terms of this well-being fall into this category. More generally, most of these 15 countries have moderately low incomes per capita and, albeit to a lesser extent, HDI values. These are characteristics of all but a few of the 30 countries listed in Table 6 . The 15 bottom ranked countries appear to be more diverse, in that there is no one characteristic which all or the bulk of them share. Among these countries are Luxemburg, Oman and Equatorial Guinea, which are ranked among the top 25 percent of the 173 country sample in terms of income per capita. Luxemburg has by far the highest PPP GDP per capita of this sample, but its ranking in terms of $\mu$ is 163 , the 11 th lowest in the sample. The bottom 15 countries also include Botswana, a middle ranked country in terms of income per capita. All of the remaining 15 lowest ranked countries in terms of $\mu_{i}$, are ranked very lowly in terms of each of $W_{i}$, the HDI and PPP GDP per capita. Botswana is ranked lowly in the first two, but not third, of these variables. 
TABLE 6

Well-Being Data; Selected Countries

\begin{tabular}{|c|c|c|c|c|c|c|c|c|c|}
\hline \multirow[b]{2}{*}{ Country } & \multicolumn{3}{|c|}{$\begin{array}{l}\text { PPP GDP } \\
\text { per capita }\end{array}$} & \multicolumn{2}{|c|}{ HDI } & \multicolumn{2}{|c|}{$\begin{array}{l}\text { Well-Being } \\
\text { Index }\end{array}$} & \multicolumn{2}{|c|}{ Residual } \\
\hline & $\begin{array}{c}\text { Value } \\
\left(y_{i}\right)\end{array}$ & $\begin{array}{l}\text { Value } \\
\left(\ln y_{i}\right)\end{array}$ & Rank & Value & Rank & $\begin{array}{l}\text { Value } \\
\left(W_{i}\right)\end{array}$ & Rank & $\begin{array}{c}\text { Value } \\
\left(\mu_{i}\right)\end{array}$ & Rank \\
\hline Tajikistan & 1152 & 7.049 & 151 & 0.667 & 112 & 0.050 & 81 & 0.177 & 1 \\
\hline Armenia & 2559 & 7.847 & 117 & 0.754 & 77 & 0.096 & 33 & 0.152 & 2 \\
\hline Uzbekistan & 2441 & 7.800 & 119 & 0.727 & 95 & 0.075 & 50 & 0.135 & 3 \\
\hline Georgia & 2664 & 7.888 & 115 & 0.748 & 81 & 0.079 & 46 & 0.131 & 4 \\
\hline Moldova, Rep. of & 2109 & 7.654 & 126 & 0.701 & 105 & 0.056 & 78 & 0.130 & 5 \\
\hline Viet Nam & 1996 & 7.599 & 128 & 0.688 & 109 & 0.040 & 89 & 0.118 & 6 \\
\hline Azerbaijan & 2936 & 7.985 & 112 & 0.741 & 89 & 0.069 & 61 & 0.113 & 7 \\
\hline Suriname & 3799 & 8.242 & 103 & 0.756 & 74 & 0.083 & 44 & 0.103 & 8 \\
\hline Cuba & 4519 & 8.416 & 90 & 0.795 & 55 & 0.095 & 35 & 0.101 & 9 \\
\hline Mongolia & 1783 & 7.486 & 134 & 0.655 & 113 & 0.012 & 106 & 0.100 & 10 \\
\hline Ecuador & 3203 & 8.072 & 110 & 0.732 & 93 & 0.064 & 64 & 0.100 & 11 \\
\hline Kyrgyzstan & 2711 & 7.905 & 114 & 0.712 & 102 & 0.048 & 84 & 0.099 & 12 \\
\hline Congo & 825 & 6.715 & 163 & 0.512 & 136 & -0.059 & 123 & 0.098 & 13 \\
\hline Philippines & 3971 & 8.287 & 97 & 0.754 & 76 & 0.081 & 45 & 0.097 & 14 \\
\hline Ukraine & 3816 & 8.247 & 102 & 0.748 & 80 & 0.074 & 52 & 0.095 & 15 \\
\hline Mauritania & 1677 & 7.425 & 136 & 0.438 & 152 & -0.196 & 157 & -0.102 & 159 \\
\hline Cote d'Ivoire & 1630 & 7.396 & 139 & 0.428 & 156 & -0.200 & 158 & -0.104 & 160 \\
\hline Vanuatu & 2802 & 7.938 & 113 & 0.542 & 131 & -0.152 & 147 & -0.104 & 161 \\
\hline Oman & 13356 & 9.500 & 40 & 0.751 & 78 & -0.016 & 114 & -0.108 & 162 \\
\hline Luxembourg & 50061 & 10.821 & 1 & 0.925 & 16 & 0.097 & 32 & -0.112 & 163 \\
\hline Mozambique & 854 & 6.750 & 160 & 0.322 & 170 & -0.270 & 170 & -0.117 & 164 \\
\hline Gambia & 1649 & 7.408 & 137 & 0.405 & 160 & -0.213 & 160 & -0.118 & 165 \\
\hline Central African Rep. & 1172 & 7.066 & 150 & 0.375 & 165 & -0.244 & 166 & -0.118 & 166 \\
\hline Botswana & 7184 & 8.880 & 64 & 0.572 & 126 & -0.093 & 132 & -0.129 & 167 \\
\hline Burkina Faso & 976 & 6.883 & 155 & 0.325 & 169 & -0.286 & 172 & -0.144 & 168 \\
\hline Djibouti & 2377 & 7.774 & 121 & 0.445 & 149 & -0.214 & 161 & -0.151 & 169 \\
\hline Equatorial Guinea & 15073 & 9.621 & 38 & 0.679 & 111 & -0.053 & 122 & -0.155 & 170 \\
\hline Guinea & 1982 & 7.592 & 129 & 0.414 & 159 & -0.235 & 165 & -0.157 & 171 \\
\hline Niger & 746 & 6.615 & 168 & 0.277 & 172 & -0.324 & 173 & -0.158 & 172 \\
\hline Angola & 2187 & 7.690 & 125 & 0.403 & 161 & -0.253 & 167 & -0.183 & 173 \\
\hline
\end{tabular}

\section{Correlates with $\mu_{i}$ : Data And Results}

$\mu_{i}$ is a purely statistical construct. Policy makers might be reluctant to, for example, monitor a residual obtained from a linear regression of a principal component on the logarithm of income per capita. A key question, therefore, concerns that variable which best individually accounts for the variation in $\mu_{i}$ across countries. Of particular interest is whether less widely available, reported or used wellbeing or well-being related indicators perform better than the standard indicators, the $x_{k, i}^{t}$ and the HDI. ${ }^{9}$ If so, then this would appear to be an a priori case for the relevant bodies to further develop and report these indicators, including expanding their country coverage. It could also provide a case for greater use of the available data on them in reporting and analyzing well-being achievement. The following simple hypotheses were therefore evaluated:

${ }^{9}$ Note that it makes no difference whether one uses $x_{k, i}^{i}$ or $x_{k, i}$ (the non-transformed variables) given the nature of the transformation. 


$$
\begin{aligned}
& H_{0}:\left|\rho_{n s, j}\right| \leq\left|\rho_{s}^{\max }\right| \\
& H_{1}:\left|\rho_{n s, j}\right|>\left|\rho_{s}^{\max }\right|
\end{aligned}
$$

where $\rho_{n s, j}$ is the correlation coefficient between $\mu_{i}$ and the $j$-th less widely available, reported or used indicator and $\rho_{s}^{\max }$ is the highest correlation coefficient between $\mu_{i}$ and the non-economic standard indicators, respectively, for the sample of countries under consideration. We shall for convenience label the former as nonstandard indicators. ${ }^{10}$ The null hypothesis is that the non-standard indicator under consideration accounts for no more of the variation in $\mu_{i}$ than the standard one that does best in this regard. The alternative hypothesis is that the former does better than the latter in empirically capturing this variation. Both zero-order (Pearson) and rank-order (Spearman) coefficients are reported. All coefficients are also subjected to the standard hypothesis test, i.e. whether they are significantly different from zero. ${ }^{11}$

Two issues need to be addressed prior to conducting the hypothesis tests. The first is measurement error. While few if any well-being indicators considered thus far are free of measurement error, arguably those subject to greatest error are the standard non-economic indicators, as defined. This is of relevance to the above hypothesis tests given its implications for $W_{i}$, as can now be demonstrated. Let the true, unobservable and measurement error free variable be $W_{i}^{*}$. Its relationship with $W_{i}$ is:

$$
W_{i}=W_{i}^{*}+\mu_{i}^{*} .
$$

where $\mu_{i}^{*}$ is the error in measuring $W_{i}^{*}$. It follows from (4) that $\mu_{i}$ is a composite variable, defined as:

$$
\mu_{i}=v_{i}+\mu_{i}^{*} .
$$

where $\nu_{i}$ is the true measure of non-economic well-being achievement, as defined above. Given (1), $\mu_{i}^{*}$ is defined as:

$$
\mu_{i}^{*}=\sum_{k=1}^{m} \Phi_{k} \mu_{k, i}^{t *}
$$

where $\mu_{k, i}^{t, *}$ are the errors in measuring $x_{k, i}^{t, *} \mu_{i}^{*}$ is thus a composite error term, with the same general structure as the well-being indicator $W_{i}$. It follows from (1), (5) and (6) that regressing $\mu_{i}$ on $x_{1, i}^{t}, x_{2, i}^{t}$ or $x_{3, i}^{t} x_{1, i}^{t} x_{2, i}^{t}$ or $x_{3, i}^{t}$, is the equivalent of regressing $\left(v_{i}^{*}+\mu_{i}\right)$ on $\left(x_{1, i}^{t, *}+\Phi_{1} \mu_{1, i}^{t, *}\right),\left(x_{2, i}^{t, *}+\Phi_{2} \mu_{2, i}^{t, *}\right)$ or $\left(x_{3, i}^{t, *}+\Phi_{3} \mu_{3, i}^{t, *}\right)$ respectively. A regression of $\mu_{i}$ on the HDI also involves regressing of $\mu_{i}^{*}$ on itself given that the HDI shares variables with $W_{i}$. The resulting correlation coefficients will therefore be distorted upwards, in absolute terms, in the sense that each regression involves

\footnotetext{
${ }^{10}$ It is acknowledged that this term is used quite loosely, as the distinction between non-standard and standard indicators is not always clear. In particular, a number of the non-standard indicators have been used for some time, and are available for large samples of countries. In this case, an indicator is in effect deemed "standard" if it has been used to form the HDI. Similarly, the term non-economic indicator, used throughout this paper, is used to simply describe an indicator that is not based on some measure of income per capita. Likewise, a non-exclusively economic indicator is one that has been partly obtained using a measure of income per capita.

${ }^{11} \mu_{i}$ and its variants were re-estimated for each of the samples for which data for the non-standard indicators were available. This is necessary to ensure that they are orthogonal with respect to $\ln y_{i}$.
} 
regressing $\mu_{i}^{*}$ on itself or one of its components. This in turn means that $\rho_{s}^{\max }$ will be distorted upwards, therefore, possibly leading to the erroneous rejection of the null hypothesis outlined above. ${ }^{12}$

Addressing this issue is less than straightforward as we are required to speculate as to likely values of $\mu_{i}^{*}$ to obtain $\nu_{i}$. $\nu_{i}$ can then be regressed on $x_{1, i}^{t}, x_{2, i}^{t}, x_{3, i}^{t}$ and the HDI to obtain a less distorted $\rho_{s}^{\max }$. The issue was addressed as follows. Given (4) and (5), we can after some algebraic manipulation write the following equation:

$$
W_{i}=\alpha+\beta \ln y_{i}+\gamma_{q} \pi_{q, i}+v_{q, i}
$$

where $\gamma_{q} \pi_{q, i}$ are alternative estimates of $\mu_{i} \pi_{q, i}^{*}$ is one $q$ variables and $\gamma_{q}$ are the corresponding parameters. A number of different formulations of $\pi_{q, i}$ and values of $\gamma_{q}$ were considered. Three formulations and values were, in the final analysis, adopted. These formulations are, of course, necessarily no more than informed guesses as to the likely values of $\mu_{i}^{*}$. No attempt was made to guestimate the $\mu_{k, i}^{t, *}$, and as such each of the $x_{k, i}^{t}$ are assumed to be approximately equally erroneously measured.

It is reasonable to assume that error in measuring $W_{i}$ will be subject to a random process but also be a decreasing function of the resources a country allocates to the collection and reporting of aggregate well-being data and the effectiveness with which these resources have been allocated. Moreover, it is also reasonable to posit that both of the second of these factors will be an increasing function of the income per capita. The formulations of $\pi_{q, i}$ are based on these assumptions. The first, $\pi_{1, i}$, was defined as a standard random variable with a mean of zero and variance of one, expressed as a ratio of the reciprocal of $\ln y_{i}$. For a given random value, therefore, $\pi_{1, i}$ will be smaller the larger is a country's income per capita and vice versa. In estimating (7) with $\pi_{1, i}$, the value of $\gamma_{1}$ was unrestricted, being determined purely by the data. This is appropriate as the resulting estimate of $\mu_{i}^{*}$ will be scaled in proportion to $W_{i}$. $\pi_{2, i}$ was defined as a random normal variable but with a mean, standard deviation and variance differing according to country group. For low- and middle-income countries the standard deviation was four and two times that of the high-income countries, respectively. $\gamma_{2}$ was determined by the data to ensure that the corresponding estimate of $\mu_{i}^{*}$ is in proportion to $W_{i}$. Finally, $\pi_{3, i}$ was defined as a uniform random number, but with its range being set according to some fraction of $W_{i}$. This fraction was set at $0.025,0.05$ and 0.20 for high-, middle- and low-income countries, respectively. $\gamma_{3}$ was restricted to one in estimating (7) with $\pi_{3, i}$.

The second issue also relates to $\rho_{s}^{\max }$ and the possible erroneous rejection of the null hypothesis outlined above. It is obvious from (1) and (2) that:

$$
\mu_{i}=\sum_{k=1}^{m} \Phi_{k} x_{k, i}^{t}-\left(\alpha+\beta \ln y_{i}\right)
$$

It follows from (8) that regressing $\mu_{i}$ on $x_{1, i}^{t}, x_{2, i}^{t}$ or $x_{3, i}^{t}$ to obtain $\rho^{\max }$ is the equivalent of regressing $\mu_{i}$ partly on itself. This also applies to regressing $\mu_{i}$ on the

\footnotetext{
${ }^{12}$ Note that the nature of this measurement error problem is different to that usually discussed in econometrics textbooks, as it involves coefficients which are pushed away from zero rather than being biased towards them.
} 
HDI. As is the case with measurement error, this in turn means that $\rho_{s}^{\max }$ will be pushed upwards, purely by construction. It might hardly be surprising, therefore, if the null is rarely rejected. This issue was addressed by first subtracting each $\Phi_{k} x_{k, i}^{t}$ from $W_{i}$ prior to regressing the latter on $\ln y_{i}$ and $\gamma_{q} \pi_{q, i}$ to obtain adjusted estimates of $v_{q, i}$, denoted as $v_{q, k, i}^{\prime}{ }^{13}$ The residuals obtained from these processes were then regressed separately on $x_{k, i}^{t}$ to obtain adjusted correlation coefficients, from which $\rho_{s}^{\max }$ is ultimately selected. ${ }^{14}$

The non-standard variables were taken from or constructed using data in the Human Development Report 2002 (UNDP, 2002) and the World Happiness Database (Veenhoven, 2002a, 2002b). The variables are categorized as follows: Human Poverty, Health Services Provision, Health Status, Survival, Education Status, Gender Bias, Gender Empowerment, Income Inequality, Governance and Happiness. There is of course overlap between these categories. The governance indicators are subjective and relate to well-being derived from civil liberties, political rights, non-violence and the like. The happiness variables are intended to measure subjective, self-assessed well-being. A full list of variables and their definitions is provided in Appendix Table A2.

Results are reported in Table $7 .{ }^{15}$ Fifty-six zero- and rank-order coefficients between the non-standard indicators and $\mu_{i}$ are reported (see the second and seventh columns of Table 7, headed $\rho_{n s, j}$ ). Thirty-five of the former and 30 of the latter are significantly different from zero. Those with the highest correlations with $\mu_{i}$, are the contraceptive prevalence, youth literacy and women professionals and technicians variables. The zero-order coefficients between these variables and $\mu_{i}$ are $0.535,0.581$ and 0.569 , respectively. The corresponding rank-order coefficients are $0.538,0.559$ and 0.374 . Only two of the variables in the income inequality, governance and happiness groups-life enjoyment and happy life years-are significantly correlated with $\mu_{i}{ }^{16}$

Evaluation of the hypotheses relating to whether the non-standard indicators perform better than their standard counterparts in accounting for the variation in estimates of $\mu_{i}$ and its variants, $v_{q, k, i}^{\prime}$, produced interesting results. The aboveoutlined null hypothesis, that $\left|\rho_{n s, j}\right| \leq\left|\rho_{s}^{\max }\right|$, cannot be rejected in favour of the alternative in almost all cases if former coefficients are obtained using estimates

\footnotetext{
${ }^{13}$ That is, $W_{i}-\Phi_{1} x_{1, i}^{t}$ was regressed on $\ln y_{i}$ and $\gamma_{1} \pi_{1, i}$ to obtain $v_{1,1, i}^{\prime}$. This was repeated, subtracting $\Phi_{2} x_{2, i}^{t}$ and then $\Phi_{3} x_{3, i}^{t}$ from $W_{i}$ to eventually obtain $v_{1,2, i}^{\prime}$ through to $v_{3,3, i}^{\prime}$. Given that $k=1,2,3$ and $q=1,2,3$, this resulted in nine residuals and in turn nine zero-order correlation coefficients and nine rank-order coefficients, for each sample, from which the $\rho_{s}^{\max }$ were obtained.

${ }^{14}$ No attempt was made to obtain adjusted correlation coefficient between $\mu_{i}$ and the HDI. This was of no practical consequence, given that the unadjusted coefficients between these variables did not qualify as $\rho_{s}^{\max }$. Note also that another method of addressing this issue is to re-estimate (1), successfully dropping each of the component variables, one at a time. This method was also used, but produced very similar results to that described above.

${ }^{15}$ Estimates of the residuals were obtained using different, non-logarthmic transformations of $y_{i}$ consistent with various alternative values of $\varepsilon$ in equation (3). Broadly similar results were obtained. These details are also available, on request, from the author.

${ }^{16}$ Appendix Table A 3 reports correlation coefficients between $\ln y_{i}$ and the variables listed in Table 7. It has been suggested that the correlations between these variables and $\mu_{i}$ will be a decreasing function of their correlations with $\ln y_{i}$, with in particular the indicator being most highly correlated with $\mu_{i}$ being that which is least correlated with $\ln y_{i}$. A comparison of the coefficients in Tables 6 and A3 shows that this is not the case. It is true that variables highly correlated with $\ln y_{i}$ tend to be least correlated with $\mu_{i}$, but the relatonship is not a systematic one in the sense suggested.
} 


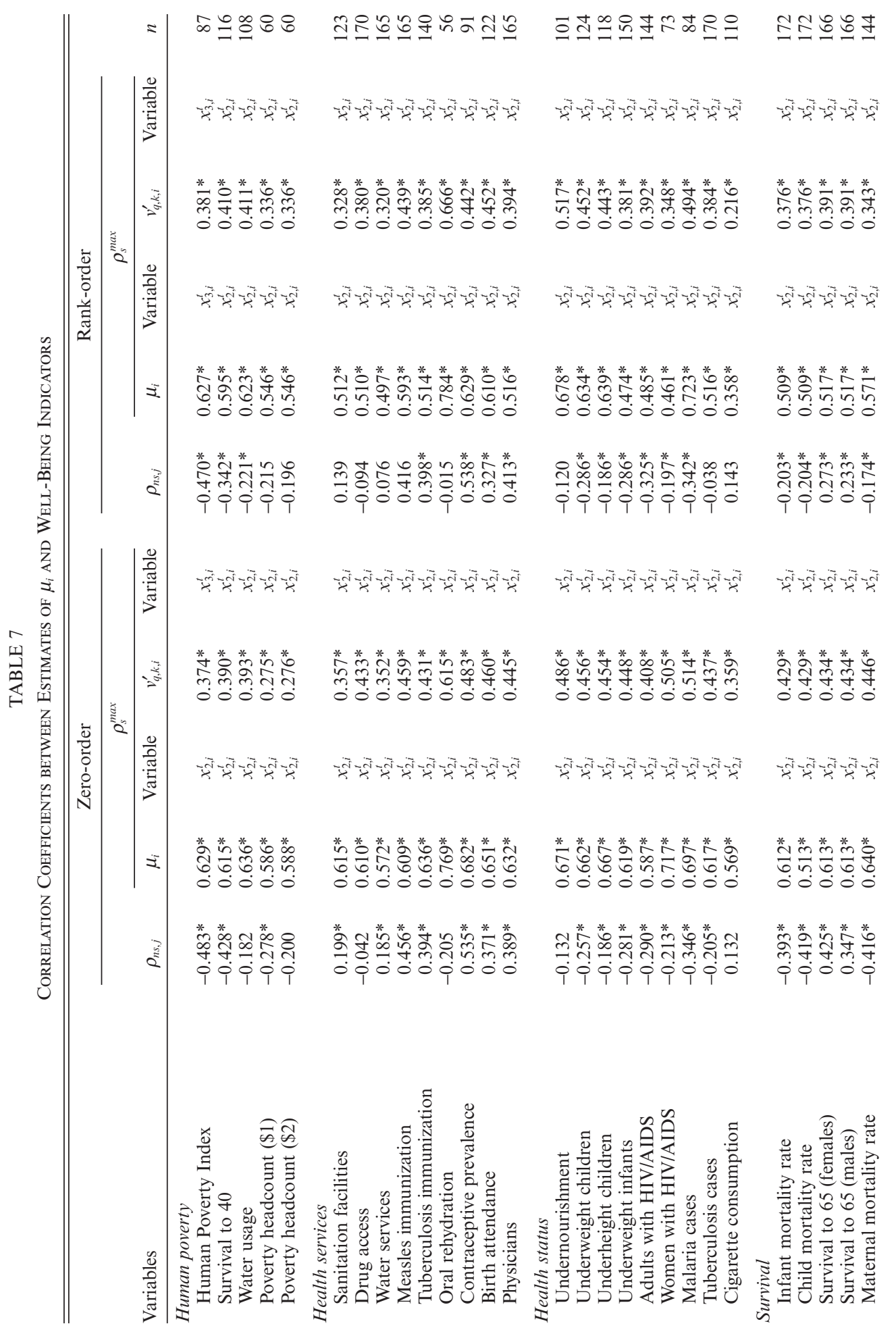




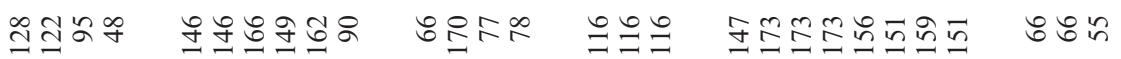

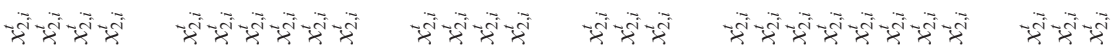

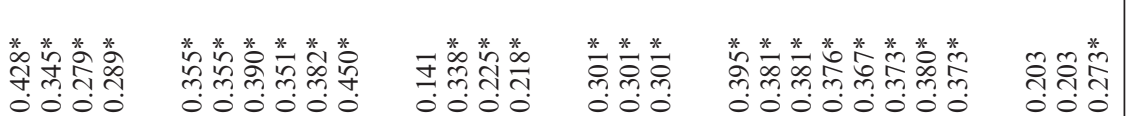

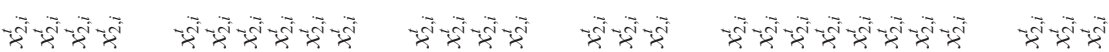

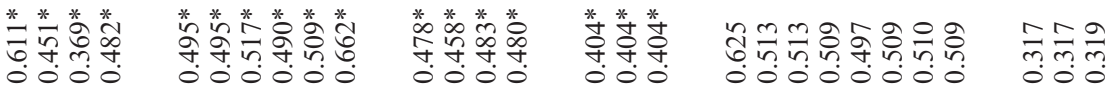

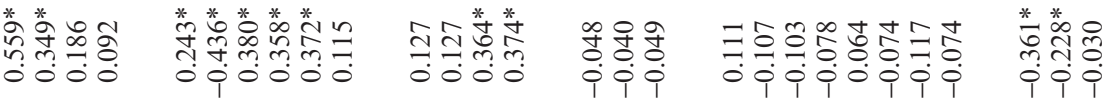

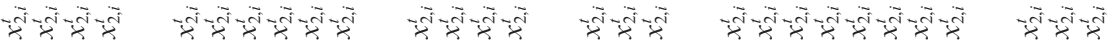

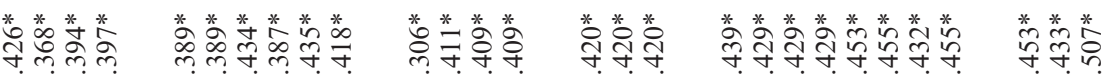

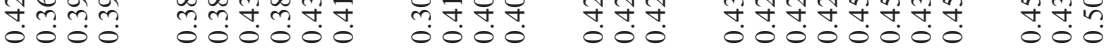

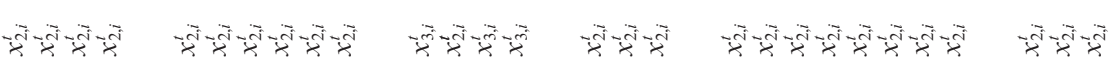

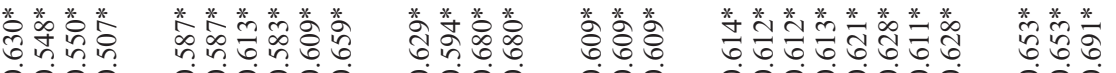

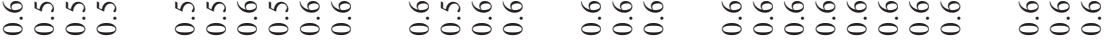

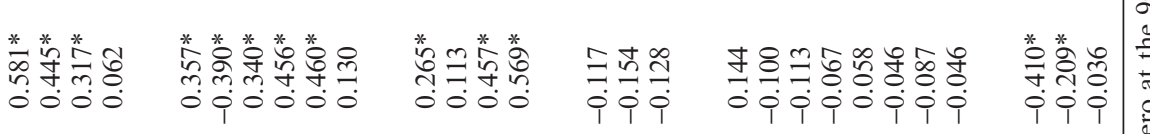

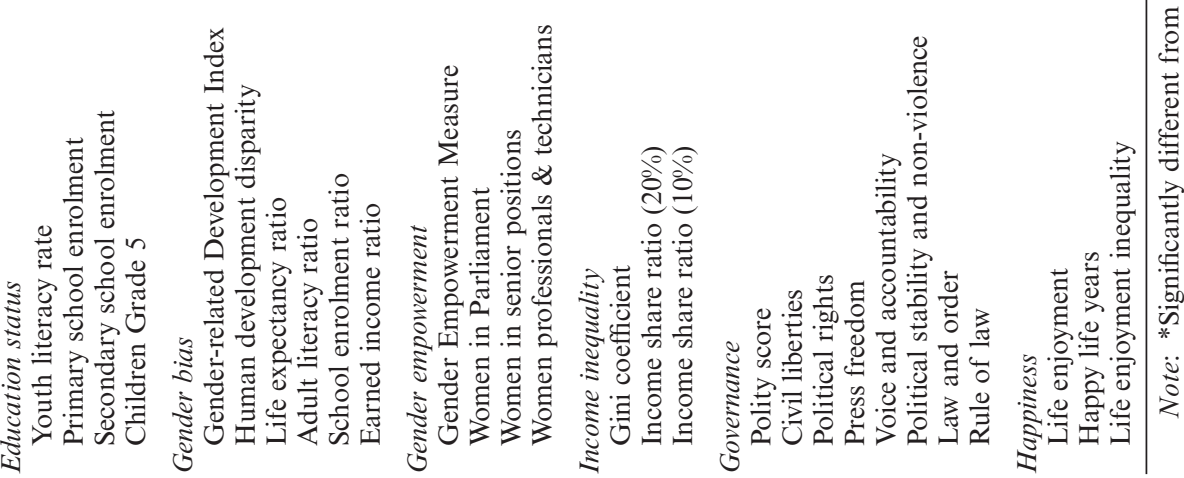


of $\mu_{i}$. As is shown in Table 7, the estimates of $\rho_{s}^{\max }$ obtained using $\mu_{i}$ are larger in absolute value than the corresponding $\rho_{n s, j}$ in all samples. These estimates are shown in the third and eight columns of Table 7, headed $\mu_{i}$. Moreover, in almost all cases the standard variable that was most correlated with $\mu_{i}$ was adult literacy $\left(x_{2, i}^{t}\right)$ (see the fourth and ninth columns of Table 7).

That the null hypothesis cannot be rejected is nor surprising given the measurement error and construction issues and resultant inflation of $\rho_{s}^{\max }$, as discussed above. Much lower values of these coefficients were obtained from regressing $v_{q, k, i}^{\prime}$ on the standard indicators. These coefficients are shown in the fifth and tenth columns of Table 7 , headed $v_{q, k, i}^{\prime}{ }^{17}$ The null hypothesis was rejected in almost all cases. The only sample for which adult literacy was not the most highly correlated variable with these adjusted residuals was that determined by the availability of the Human Poverty Index. For that sample, school enrolment $\left(x_{3, i}^{t}\right)$ was the standard indicator most highly correlated cardinally and ordinally with the chosen $v_{q, k, i}^{\prime}$. It should be noted, however, that these coefficients were not significantly higher those that between adult literacy and this residual for the same sample. ${ }^{18}$

The null hypothesis, that $\left|\rho_{n s, j}\right| \leq\left|\rho_{s}^{\max }\right|$ was ultimately rejected for two variables only: youth literacy and women professionals and technicians. This was the case for both the zero- and rank-order correlation coefficients for the former, but for the zero-order correlation for the latter indicator. There would appear, therefore, to be a case for further development and use of these indicators in the ways mentioned above.

\section{CONCLUSION}

A range of indicators has been used over recent decades in an attempt to empirically capture non-economic dimensions of human well-being. Most of the commonly used indicators, available for large country samples, are very highly correlated with various measures of income per capita. Given this they have been criticized for not being able to tell us much more than income per capita alone and, as a consequence, for not sufficiently capturing non-economic dimensions of crosscountry well-being achievement. This paper has responded to this criticism. It identified the variation in a composite of the most widely used non-economic wellbeing indicators not accounted for by income per capita. It did this by regressing this composite on the logarithm of PPP GDP per capita, observing the values of the residual term of the regression. This residual was interpreted as an incomeindependent, or non-economic, measure of national well-being achievement. Estimates of this residual were provided for 173 countries. An interesting result is that the top ranked countries, in terms of non-economic well-being achieved measured according to this residual, were dominated by those which either still have or in their recent pasts have had non-market, centrally planned economies. The bottom ranked countries were far more diverse, seemingly without a unifying, common characteristic.

\footnotetext{
${ }^{17}$ Columns 5 and 10 of Table 7 report the largest correlation coefficients obtained regressing each $v_{q, k, i}^{\prime}$ on each $x_{k, i}^{t}$. Details of all correlation coefficients are available from the author.

${ }^{18}$ Full details of these results are available from the author.
} 
The paper then looked at correlations between its measured and other less widely-used well-being indicators in an attempt to find the indicator which best captures non-economic well-being achievement. The rationale for this is that the above-mentioned residual is a purely statistical construct, derived from a series of econometric procedures. It is not what might be described as a direct measure of well-being, therefore. As it turned out, only two of the less widely-used indicators perform better in this regard than a standard indicator. Those variables were youth literacy and a gender empowerment variable, the female share of professional and technical employment. In all other cases a standard, widely-used measure performed best in this regard. That variable was the adult literacy rate. This was a particularly robust result, which was obtained consistently across different samples of countries and under different assumed error measurement scenarios.

What are the implications of these results? Most obviously, it suggests that if we wish to use a measure of well-being, in the sense defined above, that best captures this paper's notion of non-economic well-being achievement, across different samples of countries, we should be using the adult literacy rate. This is an interesting finding, to the extent that the adult literacy rate is subject to the abovementioned criticism regarding correlations with income. It is also disappointing, on the one hand, that there have been many attempts to shift focus away from the standard measures, including adult literacy, towards newer, hopefully more enlightening indicators. On the other hand, it is not disappointing, given that such a widely used measure performs so consistently well in capturing non-economic well-being achievement. With regard to the female share of technical and professional employment and youth literacy variables, there would appear to be a case for expanding the coverage, reporting and usage of these indicators if one is to comprehensively measure non-economic well-being achievement with a variable other than one obtained by construction, using econometric techniques. Greater coverage of the former variable would appear to be especially warranted, given that it is available for a relatively small sample of countries. A message for policy from this result is that if we want to promote non-economic well-being, as defined in this paper, we should continue to strive for improvements in adult literacy. This message is made stronger given the result for youth literacy.

Finally, let us consider some possible directions for future research. First, while this paper has made some attempt to account for measurement error in the standard indicators, further work on this is clearly required both at a conceptual level, involving further consideration of the source of measurement error, and at the purely empirical level. The nature of the errors might be different or more complicated than envisaged in this paper. As such it is not beyond the bounds of imagination to speculate that the correlation between the variants of $\mu_{i}$ and adult literacy is due to errors in measurement not captured in this paper. Further tests for the sensitivity of this result to possible measurement error would appear to be warranted, therefore. Second, there is far from universal acceptance that a logarithmic transformation of income per capita, used in this paper, is appropriate. Alternative transformations could be investigated. Third, non-economic achievement could be measured using period-averages of the relevant data instead of data for a single year. This might better capture long-run relationships between income and the non-economic indicators. Fourth, one could account for possible 
endogeneity between income and the non-economic indicators in estimating the residual between them. Fifth, rather than seeking to correlate this paper's measure of non-economic well-being achievement on a single variable, one could look at correlating it against a composite of a number of indicators, thereby providing a multidimensional non-economic well-being achievement indicator. Finally, rather than seeking a variable or variables which are merely associated with the paper's constructed measure of well-being achievement, one could undertake a far more sophisticated analysis that looks for causal relationships. 


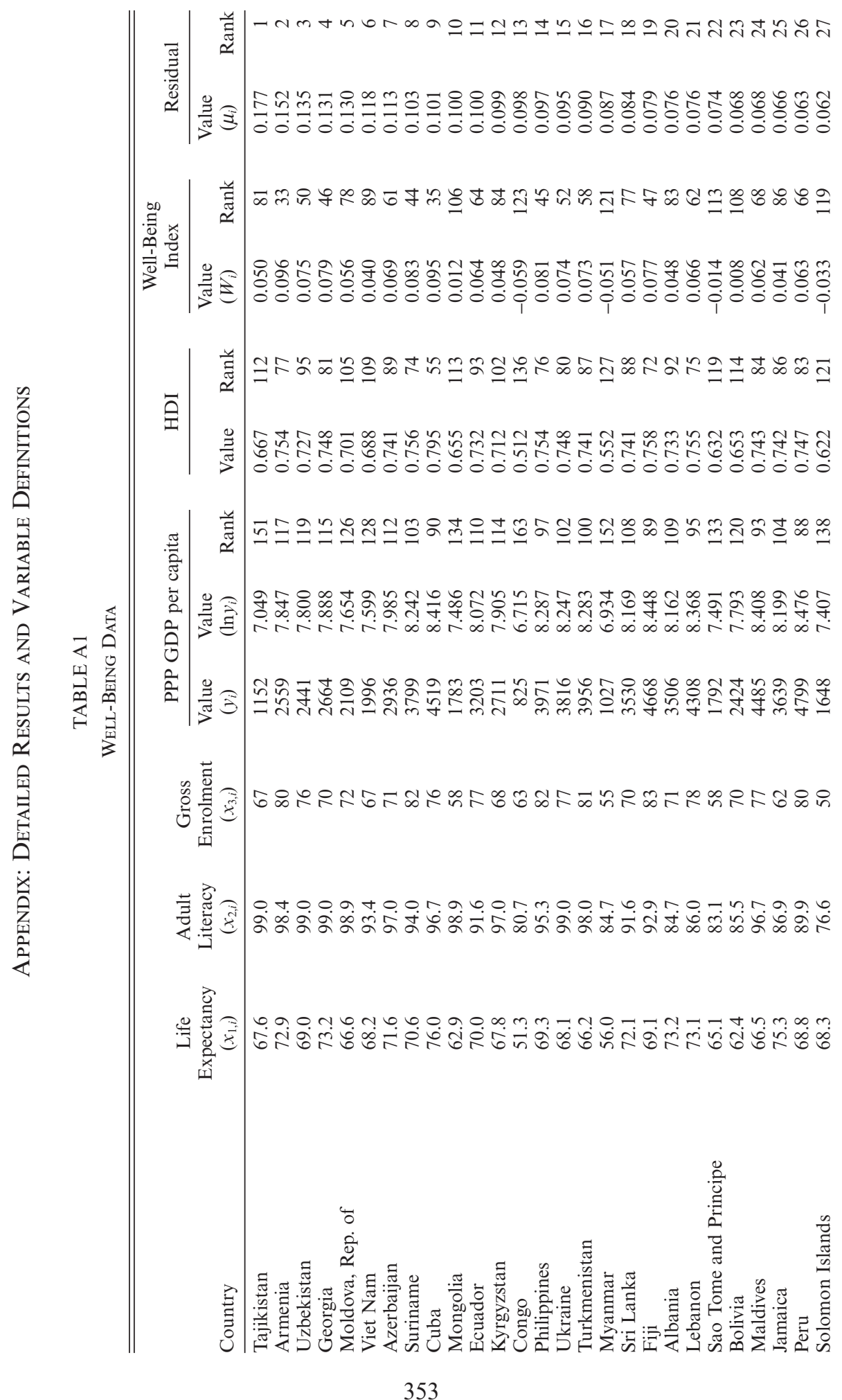




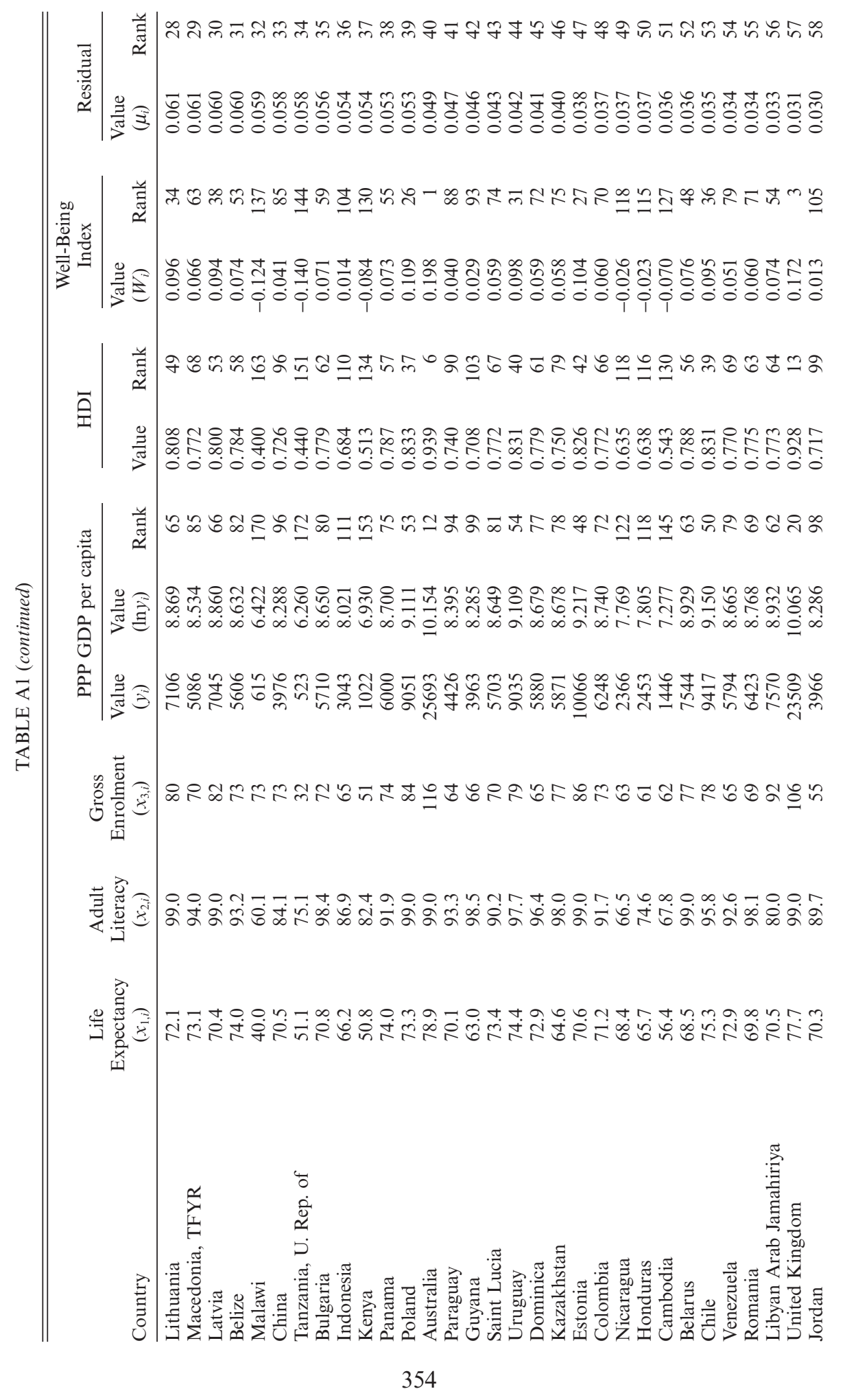


ウ̊ロ

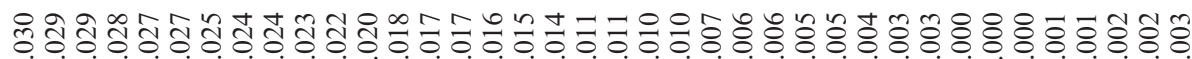

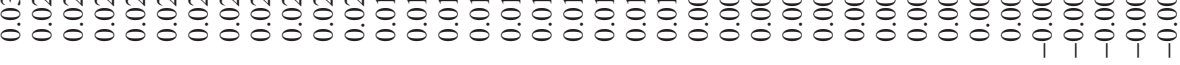

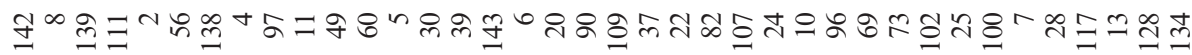

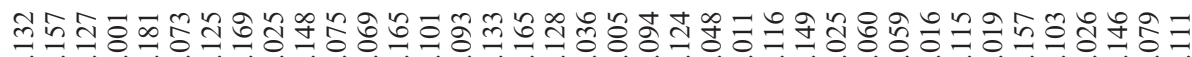

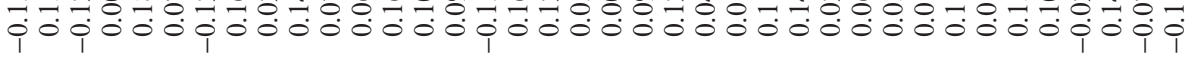

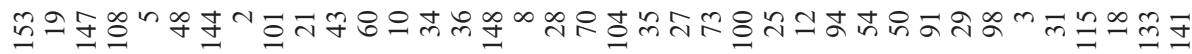

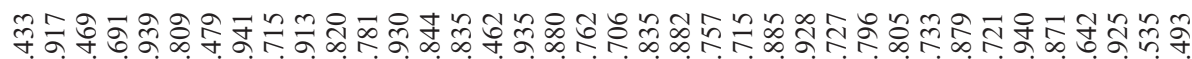

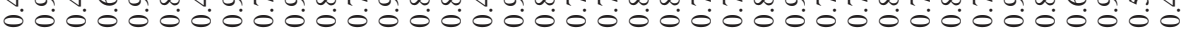

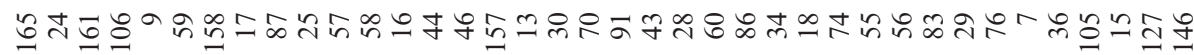

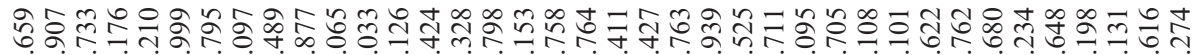

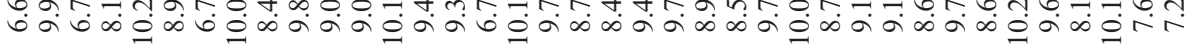

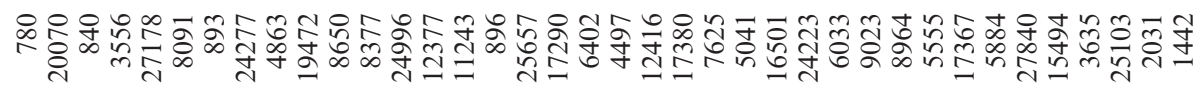

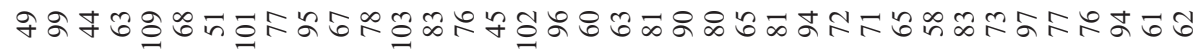

๙

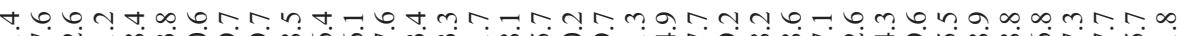

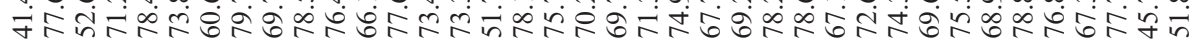

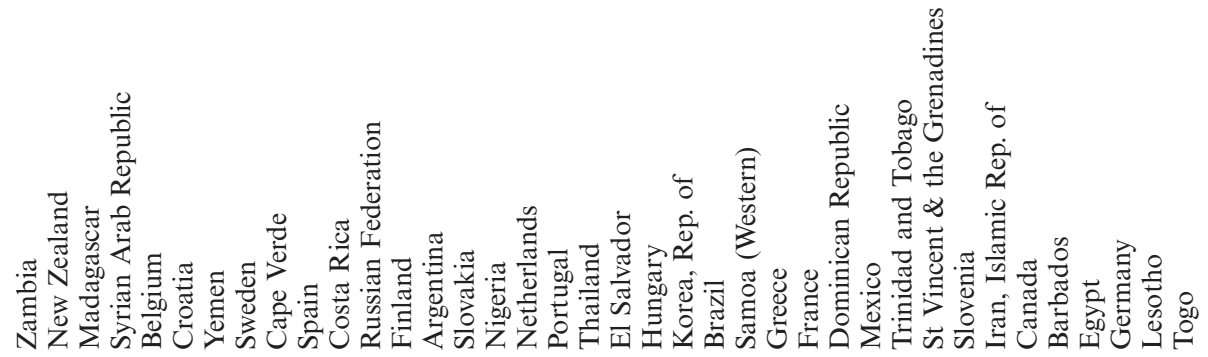




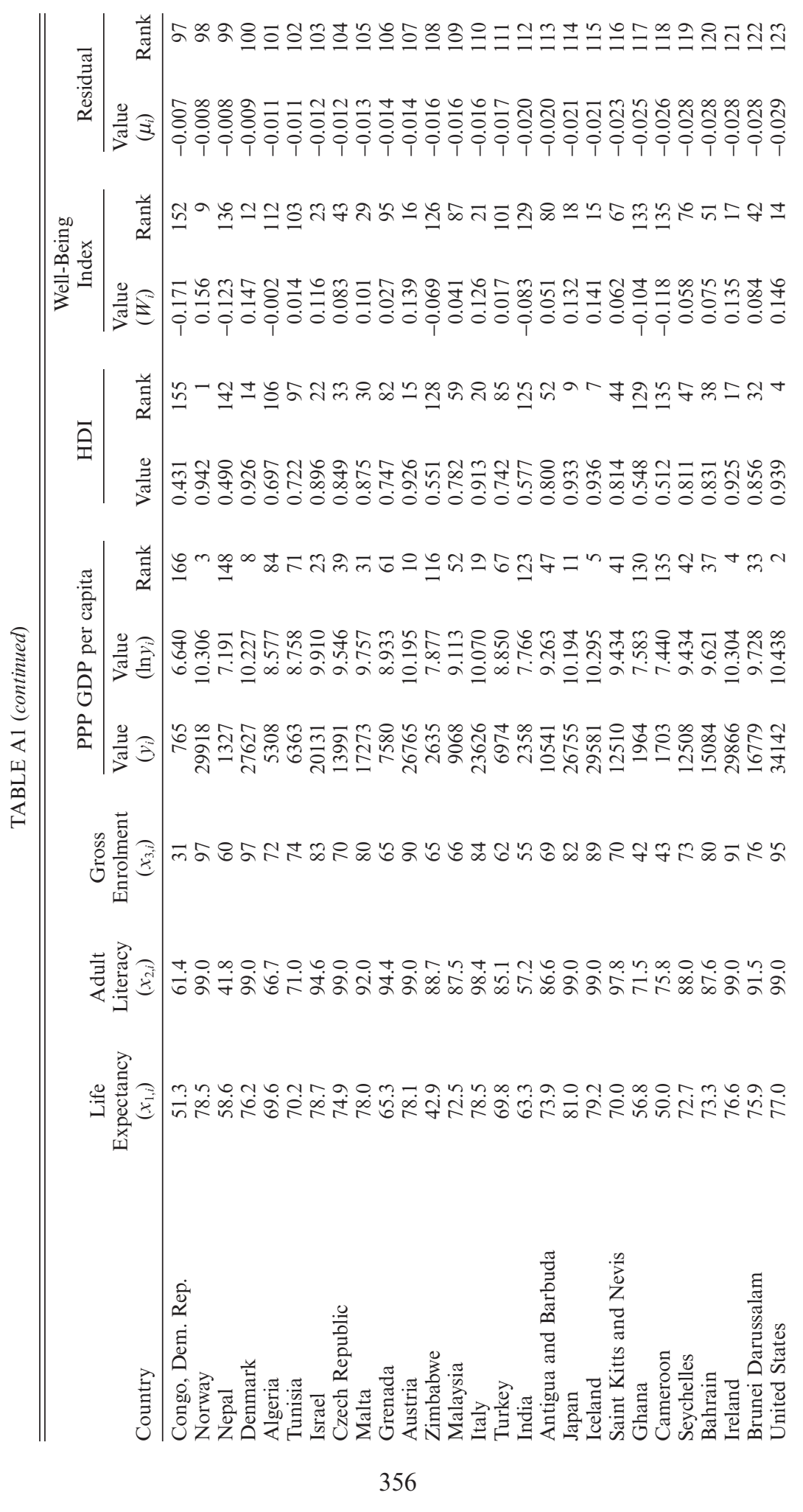




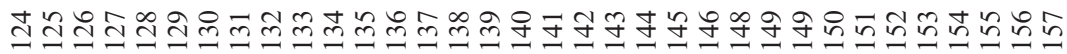

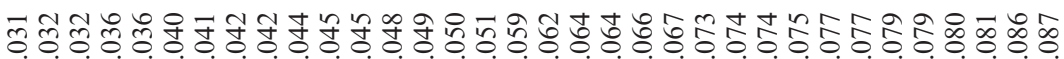

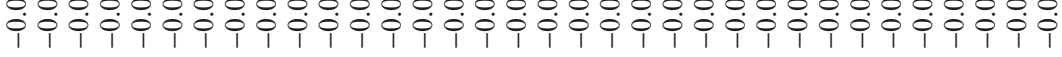

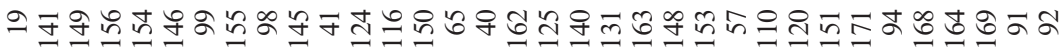

สิ -

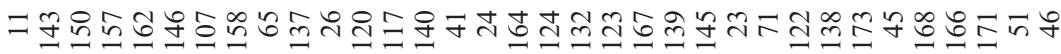

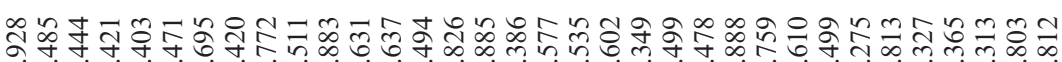

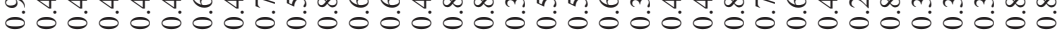

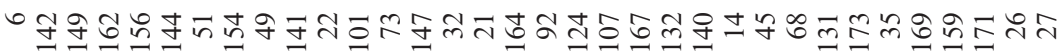

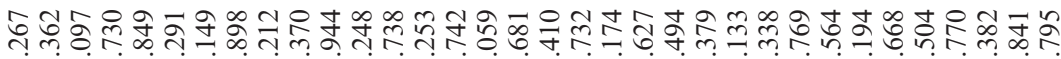

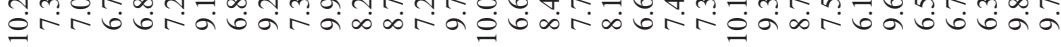

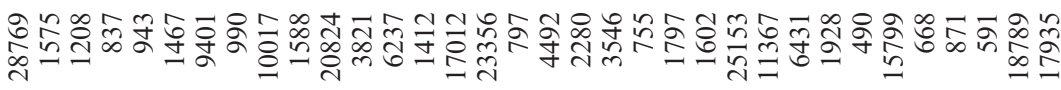

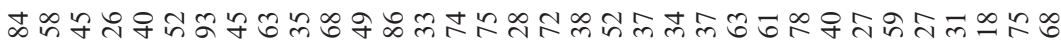

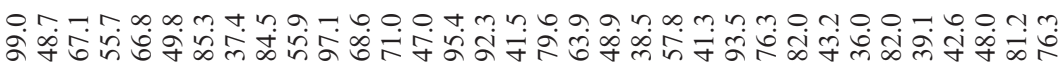

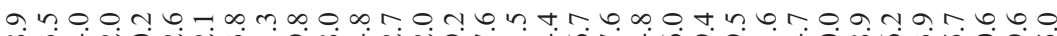

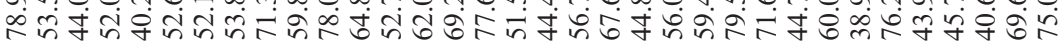

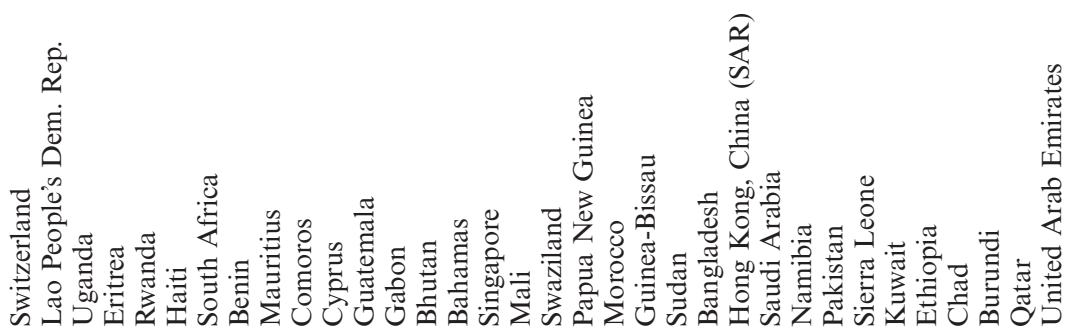




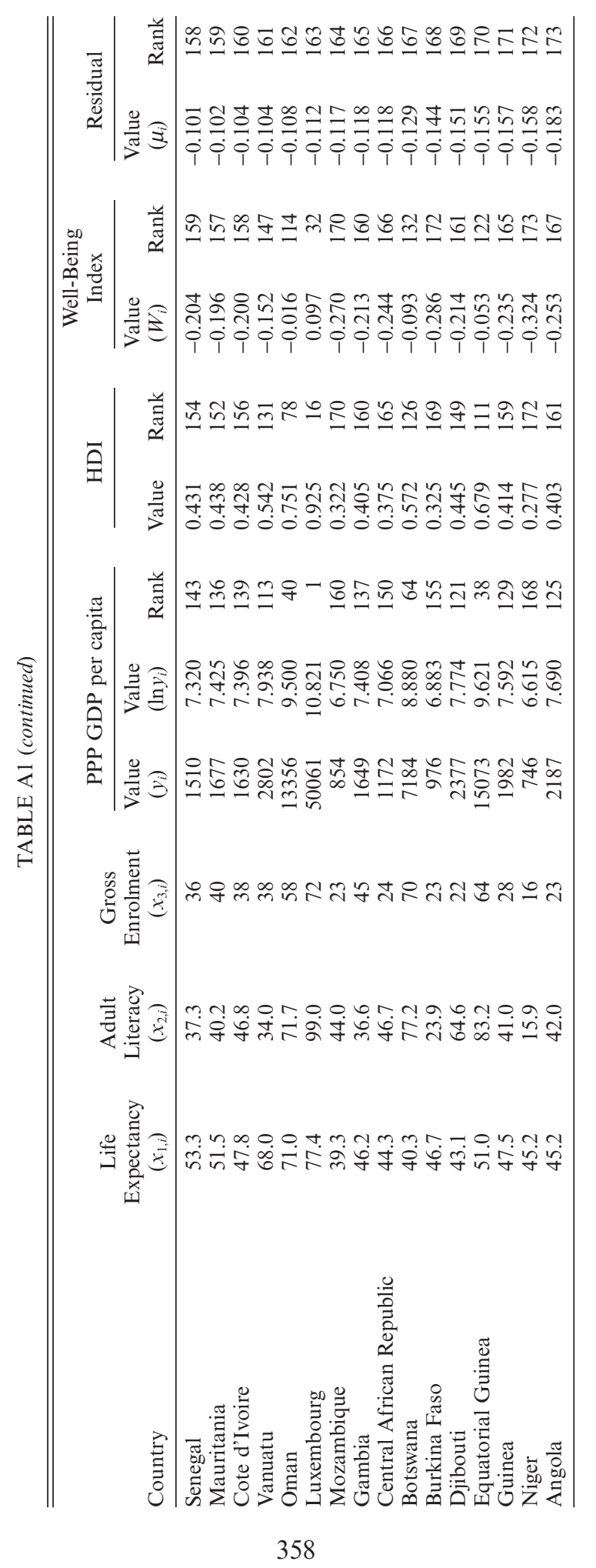


TABLE A2

VARIABLE Definitions

\begin{tabular}{l}
\hline Variable \\
Human Development \\
Index
\end{tabular}

Life expectancy

Adult literacy

Gross enrolment

Human Poverty Index (HPI-1)

Survival to 40

Water usage

Poverty headcount (\$1)

Poverty headcount (\$2)

Sanitation facilities

Drug access

Water services

Measles immunization

Tuberculosis

immunization

Oral rehydration

Contraceptive

prevalence
Year and Definition

2000. Human Development Index value - a composite index combining measures of life expectancy, adult literacy, school enrolment and PPP GDP per capita.

2000. Life expectancy at birth (years) - the number of years a newborn infant would live if prevailing patterns of age-specific mortality rates at the time of birth were to stay the same throughout the child's life.

2000. Adult literacy rate - the percentage of people aged 15 and above who can, with understanding, both read and write a short, simple statement on their everyday life.

1999. Combined primary, secondary and tertiary gross enrolment ratio $(\%)$ - the number of students enrolled in a level of education, regardless of age, as a percentage of the population of official school age for that level.

2000. Human poverty index value - a composite index combining measures of lack of access to improved water services, probability of not surviving to age 40 , underweight children and adult illiteracy.

1995-2000. Probability at birth of not surviving to age 40 ( $\%$ of cohort) - calculated as 1 minus the probability of surviving to a specific age for a given cohort.

2000. Population not using improved drinking water sources (\%)calculated as 100 minus the percentage of the population using any of the following types of water supply for drinking: piped water, a public tap, a borehole with a pump, a protected well, a protected spring or rainwater.

1983-2000. Percentage of the population living below income poverty line set at $\$ 1$ a day in 1985 prices (\$1.08 in 1993 prices), adjusted for purchasing power parity.

1983-2000. Percentage of the population living below income poverty line set at \$2 a day in 1985 prices (\$2.16 in 1993 prices), adjusted for purchasing power parity.

2000. Population using adequate sanitation facilities (\%) - the percentage of this population using adequate sanitation facilities, such as a connection to a sewer or septic tank system, a pour-flush latrine, a simple pit latrine or a ventilated improved pit latrine. An excreta disposal system is considered adequate if it is private or shared (but not public) and if it hygienically separates human excreta from human contact.

1999. Population with access to essential drugs (\%) - the percentage of the population for whom a minimum of 20 of the most essential drugs are continuously and affordably available at public or private health facilities or drug outlets within one hour's travel from home.

2000. Population using improved water services (\%) - the proportion of the population using piped water, water from a public tap, water from a borehole with a pump, water from a protected well or protected spring or rainwater for drinking.

1999. One-year-olds fully immunized against tuberculosis (\%).

1999. One-year-olds fully immunized against measles (\%).

1994-2000. Oral rehydration therapy use rate (\%) - the percentage of all cases of diarrhoea in children under age five treated with oral rehydration salts or recommended home fluids, or both.

1995-2000. Contraceptive prevalence (\%) - the percentage of married women aged 15-49 who are using, or whose partners are using, any form of contraception, whether modern or traditional. 
TABLE A2 (continued)

\begin{tabular}{ll}
\hline \hline Variable & Year and Definition \\
\hline Birth attendance & $\begin{array}{l}\text { 1994-2000. Births attended by skilled health staff }(\%) \text { - the percentage of } \\
\text { deliveries attended by a doctor, nurse or midwife or trained traditional } \\
\text { birth attendant. }\end{array}$
\end{tabular}

Physicians

Undernourishment

Underweight children

1990-1999. Physicians (per 100,000 people) —includes graduates of a faculty or school of medicine who are working in any medical field (including teaching, research and administration)

1997-99. Undernourished people (as \% of total population) - people whose food intake is insufficient to meet their minimum energy requirements on a chronic basis.

Under height children 1995-2000. Underweight children under age five (\%) - includes moderate and severe underweight, which is defined as below two standard deviations from the median weight for age of the reference population.

Under height children 1995-2000. Children under height for age (\% under age 5) —includes moderate and severe stunting, which is defined as below two standard deviations from the median height for age of the reference population.

Underweight infants

Adults with HIV/AIDS 1995-2000. Infants with low birth-weight (\%) - the percentage of infants with a birth-weight of less than 2,5000 grams.

Women with HIV/AIDS 2001. People living with HIV/AIDS, adults (\% age 15-49) - the estimated number of people living with HIV/ADIS at the end of the year specified.

Women with HIV/AIDS

2001. People living with HIV/AIDS, women (\% age 15-49) - the estimated number of people living with HIV/AIDS at the end of the year specified.

Malaria cases

Tuberculosis cases

Cigarette consumption

2000. Malaria cases (per 100,000 people) — the total number of malaria cases reported to the World Health Organization by countries in which malaria is endemic.

1999. Tuberculosis cases (per 100,000 people) - the total number of tuberculosis cases reported to the World Health Organization. A tuberculosis case is defined as a patient in whom tuberculosis has been bacteriologically confirmed or diagnosed by a clinician.

1999-2000. Cigarette consumption per adult (annual average) — the sum of production and imports minus exports of cigarettes divided by the population aged 15 and above.

Infant mortality rate 2000. Infant mortality rate (per 1,000 live births) - the probability of dying between birth and exactly one year of age expressed per 1,000 live births.

Child mortality rate

Survival to 65 (females)

2000. Under-five mortality rate (per 1,000 live births) - the probability of dying between birth and exactly five years of age expressed per 1,000 live births.

1995-2000. Probability at birth of surviving to age 65 , female ( $\%$ of cohort) - the probability of a newborn infant surviving to a specified age if subject to prevailing patterns of age-specific mortality rates.

Survival to 65 (males)

Maternal mortality rate 1995-2000. Probability at birth of surviving to age 65 , male ( $\%$ of cohort) - the probability of a newborn infant surviving to a specified age if subject to prevailing patterns of age-specific mortality rates.

1985-99. Maternal mortality ratio reported (per 100,000 live births) reported annual number of deaths of women from pregnancy-related causes per 100,000 live births, not adjusted for the well-documented problems of underreporting and misclassification.

Youth literacy rate

2000. Youth literacy rate ( $\%$ age $15-24)$ - the percentage of people aged 15-24 who can, with understanding, both read and write a short, simple statement on their everyday life. 
TABLE A2 (continued)

\begin{tabular}{l}
\hline Variable \\
\hline Primary school
\end{tabular}

enrolment

Secondary school enrolment

Children Grade 5

Gender-related Development Index

Human development disparity

Life expectancy ratio

Adult literacy ratio

School enrolment ratio

Earned income ratio

Gender empowerment measure

Women in Parliament

Women in senior positions

Women professionals and technicians

Gini coefficient

Income share ratio $(20 \%)$

Income share ratio $(10 \%)$

Polity score

Civil liberties

Political rights

Press freedom
Year and Definition

1998. Net primary enrolment ratio (\%) - the number of students enrolled in a level of education who are of official school age for that level, as a percentage of the population of official school age for that level.

1998. Net secondary enrolment ratio (\%) - the number of students enrolled in a level of education who are of official school age for that level, as a percentage of the population of official school age for that level. 1995-97. Children reaching grade $5(\%)$ - the percentage of children starting primary school who eventually attain grade 5 (grade 4 if the duration of primary school is four years). The estimates are based on the reconstructed cohort method, which uses data on enrolment and repeaters for two consecutive years.

2000. Gender-related development index (GDI) value - the HDI but with its components adjusted for inequalities between men and women.

2000. Ratio of the Human Development Index to the Gender-related Development Index.

2000. Ratio female to male life expectancy at birth.

2000. Ratio of female to male adult literacy rate.

2000. Ratio of female to male combined primary, secondary and tertiary gross enrolment ratio.

2000. Ratio of female to male estimated earned income-each income is roughly derived on the basis of the ratio of the female non-agricultural wage to the male non-agricultural wage, the female and male shares of the economically active population, total female and male population and GDP per capita (PPP US\$).

1991-2002. Gender empowerment measure (GEM) value - a composite index combining measures in gender inequality in parliamentary seats, legislative, senior official and managerial positions, professional and technical employment and earned income.

2002. Seats in parliament held by women (as \% of total) - refers to seats held by women in a lower or single house or an upper house or senate, where relevant.

1991-2000. Female legislators, senior officials and managers (as \% of total) - women's share of positions defined according to the International Standard Classification of Occupations (ISCO-88).

1991-2000. Female professional and technical workers (as \% of total) women's share of positions defined according to the International Standard Classification of Occupations (ISCO-88)

Various years. Gini coefficient values expressed as percentages.

Various years. Ratio of income or consumption share of the richest 20 percent of the population to that of the poorest 20 percent, expressed as a percentage.

Various years. Ratio of income or consumption share o the richest ten percent of the population to that of the poorest ten percent, expressed as a percentage.

2000. A subjective measure of the extent to which laws and institutions which allow for democratic participation are present.

2000. A subjective, Freedom House assessment of nations based upon the observance of civil liberties.

2000. A subjective, Freedom House assessment of nations based upon the observance of political rights.

2000. A subjective, Freedom House assessment of whether nations have a free press. 
TABLE A2 (continued)

\begin{tabular}{ll}
\hline \hline Variable & Year and Definition \\
\hline Voice and accountability & $\begin{array}{l}\text { 2000-01. A subjective assessment, based on surveys of public perception } \\
\text { regarding the quality of national governance, taking into account } \\
\text { political process, civil liberties, political rights and press freedom and } \\
\text { independence. }\end{array}$ \\
2001-01. A subjective assessment, based on surveys of public perception \\
Political stability and & $\begin{array}{l}\text { 2001. Subjective law and order measure from the International Country } \\
\text { non-violence }\end{array}$ \\
Law and order & $\begin{array}{l}\text { 2000-01. A subjective assessment, based on surveys of public perception } \\
\text { regarding the quality of national governance. }\end{array}$ \\
Rule of low & $\begin{array}{l}\text { 1990s. Self-assessed subjective enjoyment of life, based on information } \\
\text { obtained from surveys. Respondents are asked to assess their life } \\
\text { satisfaction on scale of one to ten, and a national average is derived } \\
\text { from these individual assessments. } \\
\text { Life enjoyment }\end{array}$ \\
1990s. Happiness adjusted life years. National life enjoyment multiplied \\
by years of life expectancy at birth. \\
1990s. Inequality in happiness among nations. Obtained by taking the \\
standard deviation of national life enjoyment.
\end{tabular}

Source: Governance variables_-UNDP (2002); Happiness variables_-Veenhoven (2002a, 2002b).

TABLE A3

Correlations between PPP GDP Per capita (log) and Well-Being Indicators

\begin{tabular}{|c|c|c|c|}
\hline Variables & Zero-order & Rank-order & $n$ \\
\hline \multicolumn{4}{|l|}{ Human development } \\
\hline Human Development Index & 0.923 & 0.938 & 173 \\
\hline Life expectancy & 0.794 & 0.840 & 173 \\
\hline Adult illiteracy & 0.701 & 0.705 & 173 \\
\hline Gross enrolment & 0.792 & 0.780 & 173 \\
\hline Well-being Index $\left(W_{i}\right)$ & 0.833 & 0.838 & 173 \\
\hline \multicolumn{4}{|l|}{ Human poverty } \\
\hline Human Poverty Index (HPI-1) & -0.816 & -0.829 & 87 \\
\hline Survival to 40 & -0.733 & -0.773 & 116 \\
\hline Water usage & -0.676 & -0.719 & 108 \\
\hline Poverty headcount (\$1) & -0.700 & -0.709 & 60 \\
\hline Poverty headcount (\$2) & -0.790 & -0.790 & 60 \\
\hline \multicolumn{4}{|l|}{ Health services } \\
\hline Sanitation facilities & 0.643 & 0.674 & 123 \\
\hline Drug access & 0.626 & 0.675 & 170 \\
\hline Water services & 0.676 & 0.699 & 122 \\
\hline Measles immunization & 0.315 & 0.445 & 165 \\
\hline Tuberculosis immunization & 0.524 & 0.482 & 140 \\
\hline Oral rehydration & 0.161 & -0.017 & 56 \\
\hline Contraceptive prevalence & 0.678 & 0.698 & 91 \\
\hline Birth attendance & 0.768 & 0.789 & 122 \\
\hline physicians & 0.607 & 0.696 & 165 \\
\hline \multicolumn{4}{|l|}{ Health status } \\
\hline Undernourishment & -0.706 & -0.714 & 101 \\
\hline Underweight children & -0.681 & -0.713 & 124 \\
\hline Underheight children & -0.761 & -0.774 & 118 \\
\hline Underweight infants & -0.593 & -0.623 & 150 \\
\hline Adults with HIV/AIDS & -0.292 & 0.447 & 144 \\
\hline Women with HIV/AIDS & -0.054 & -0.033 & 73 \\
\hline
\end{tabular}


TABLE A3 (continued)

\begin{tabular}{|c|c|c|c|}
\hline Variables & Zero-order & Rank-order & $n$ \\
\hline Malaria cases & -0.379 & -0.463 & 84 \\
\hline Tuberculosis cases & -0.328 & -0.602 & 170 \\
\hline Cigarette consumption & 0.693 & 0.728 & 110 \\
\hline \multicolumn{4}{|l|}{ Survival } \\
\hline Infant mortality rate & -0.823 & -0.892 & 172 \\
\hline Child mortality rate & -0.800 & -0.896 & 172 \\
\hline Survival to 65 (females) & 0.797 & 0.851 & 166 \\
\hline Survival to 65 (males) & 0.756 & 0.846 & 166 \\
\hline Maternal mortality rate & -0.756 & -0.847 & 144 \\
\hline \multicolumn{4}{|l|}{ Education status } \\
\hline Youth literacy rate & 0.649 & 0.665 & 128 \\
\hline Primary school enrolment & 0.655 & 0.573 & 122 \\
\hline Secondary school enrolment & 0.871 & 0.849 & 95 \\
\hline Children Grade 5 & 0.716 & 0.826 & 48 \\
\hline \multicolumn{4}{|l|}{ Gender bias } \\
\hline Gender-related Development Index & 0.932 & 0.944 & 146 \\
\hline Human development disparity & -0.513 & -0.582 & 146 \\
\hline Life expectancy ratio & 0.347 & 0.407 & 166 \\
\hline Adult literacy ratio & 0.643 & 0.673 & 149 \\
\hline School enrolment ratio & 0.340 & 0.395 & 162 \\
\hline Earned income ratio & 0.347 & 0.322 & 90 \\
\hline \multicolumn{4}{|l|}{ Gender empowerment } \\
\hline Gender empowerment measure & 0.806 & 0.826 & 66 \\
\hline Women in Parliament & 0.403 & 0.391 & 170 \\
\hline Women in senior positions & 0.058 & -0.068 & 77 \\
\hline Women professionals \& technicians & -0.002 & -0.023 & 78 \\
\hline \multicolumn{4}{|l|}{ Income inequality } \\
\hline Gini coefficient & -0.434 & -0.438 & 116 \\
\hline Income share ratio $(20 \%)$ & -0.324 & -0.375 & 116 \\
\hline Income share ratio $(10 \%)$ & -0.300 & -0.356 & 116 \\
\hline \multicolumn{4}{|l|}{ Governance } \\
\hline Polity score & 0.394 & 0.527 & 147 \\
\hline Civil liberties & -0.540 & -0.575 & 173 \\
\hline Political rights & -0.522 & -0.579 & 173 \\
\hline Press freedom & -0.530 & -0.545 & 173 \\
\hline Voice and accountability & 0.676 & 0.662 & 156 \\
\hline Political stability and non-violence & 0.748 & 0.772 & 151 \\
\hline Law and order & 0.809 & 0.784 & 159 \\
\hline Rule of law & 0.784 & 0.772 & 151 \\
\hline \multicolumn{4}{|l|}{ Happiness } \\
\hline Life enjoyment & 0.419 & -0.115 & 66 \\
\hline Happy life years & 0.656 & 0.663 & 66 \\
\hline Life enjoyment inequality & -0.556 & -0.667 & 55 \\
\hline
\end{tabular}

\section{REFERENCES}

Alkire, S., "Dimensions of Human Development," World Development, 30, 181-205, 2002.

Anand, S. and A. Sen, "The Income Component of the Human Development Index," Journal of Human Development, 1, 83-106, 2000.

Cahill, M., "Is the Human Development Index Redundant?," Eastern Economic Journal, 12-19, 2005.

Cummins, R. A., "Domains of Life Satisfaction: An Attempt to Order Chaos," Social Indicators Research, 38, 303-28, 1996. 
Doyal, L. and I. Gough, "Need Satisfaction as an Measure of Human Welfare," in W. Glass and J. Foster (eds), Mixed Economies in Europe, Edward Elgar, London, 1993.

Drèze, J. and A. Sen, Hunger and Public Action, Oxford University Press, Oxford, 1991.

Fielding, D., "Why is Africa so Poor? A Structural Model of Economic Development and Income Inequality," Centre for the Study of African Economies Working Paper WPS/2001-5, Center for the Study of African Economies, Oxford, 2001.

—, "Health and Wealth: A Structural Model of Social and Economic Development," Review of Development Economics, 6, 393-414, 2002.

Finnis, J., Natural Law and Natural Rights, Clarendon Press, Oxford, 1980.

Galtung, J., Human Rights in Another Key, Polity Press, Cambridge, 1994.

Hicks, N. and P. Streeten, "Indicators of Development: The Search for a Basic Needs Yardstick," World Development, 7, 567-80, 1979.

Klasen, S., "Measuring Poverty and Deprivation in South Africa," The Review of Income and Wealth, 46(1), 33-58, 2000.

Lai, D., "Temporal Analysis of Human Development Indicators: Principal Component Approach," Social Indicators Research, 51, 331-66, 2000.

Larson, D. A. and W. T. Wilford, "The Physical Quality of Life Index: A Useful Social Indicator?," World Development, 7, 581-4, 1979.

McGillivray, M., "The Human Development Index: Yet Another Redundant Composite Development Indicator?," World Development, 19, 1461-8, 1991.

McGillivray, M. and H. White, "Measuring Development? The UNDP's Human Development Index," Journal of International Development, 5, 183-92, 1993.

Morris, M. D., Measuring the Conditions of the World's Poor: The Physical Quality of Life Index, Pergamon, New York, 1979.

Narayan, D., Voices of the Poor. Volume 1: Can Anyone Hear Us?, Oxford University Press, New York, 2000.

Noorbakhsh, F., "The Human Development Index: Some Technical Issues and Alternative Indices," Journal of International Development, 10, 589-605, 1998.

Nussbaum, M., "Nature, Function and Capability: Aristotle on Political Distribution," Oxford Studies in Ancient Philosophy, Supplementary Volume 6, Clarendon Press, Oxford, 1988.

Ogwang, T., "The Choice of Principal Variables for Computing the Human Development Index," World Development, 19, 2011-14, 1994.

Qizilbash, M., "Capabilities, Well-being and Human Development: A Survey," Journal of Development Studies, 33, 143-62, 1996.

Ram, R., "Composite Indices of Physical Quality of Life, Basic Needs Fulfilment, and Income: A 'Principal Component' Representation," Journal of Development Economics, 11, 227-47, 1982.

Ranis, G., F. Stewart, and A. Ramirez, "Economic Growth and Human Development," World Development, 28, 197-219, 2000.

Sen, A. K., "Development as Capability Expansion," in K. Griffin and J. Knight (eds), Human Development and the International Development Strategy for the 1990s, Macmillan, London, 1990.

—, "Capability and Well-being," in A. Sen and M. C. Nussbaum (eds), The Quality of Life, Clarendon Press, Oxford, 1993.

Srinivasan T. N., "Human Development: A New Paradigm or Reinvention of the Wheel?," American Economic Review Papers and Proceedings, 84, 238-43, 1994.

Stewart, F., "Basic Needs, Capabilities and Human Development," in A. Offer (ed.), Pursuit of the Quality of Life, Oxford University Press, Oxford, 1996.

United Nations Development Program (UNDP), Human Development Report, Oxford University Press, New York, 1990-2004.

Veenhoven, R., "Happy Life Years in 67 Nations in the 1990s, "World Database of Happiness, Rank Report 2002/2, www.eur.nl/fsw/research/happiness, 2002a.

_ _ "Equality of Happiness in 59 Nations in the 1990s, "World Database of Happiness, Rank Report 2002-3, www.eur.nl/fsw/research/happiness, 2002a.

Whistler, D., K. J. White, S. D. Wong, and D. Bates, SHAZAM User's Reference Manual Version 9, Northwest Econometrics, Vancouver, 2001. 